\title{
Lenalidomide Analog KPG-121
}

National Cancer Institute

\section{Source}

National Cancer Institute. Lenalidomide Analog KPG-121. NCI Thesaurus. Code C162878.

A lenalidomide analog with potential anti-angiog enic and immunomodulatory activities.

Upon oral administration, lenalidomide analog KPG-121 may inhibit tumor necrosis factor alpha (TNF-alpha) production, stimulate T-lymphocytes, reduce serum levels of vascular endothelial growth factor (VEGF) and basic fibroblast growth factor (bFGF; FGF2), and inhibit angiogenesis. Additionally, KPG-121 may promote G1 cell cycle arrest and induce apoptosis in malignant cells. 